\title{
EDITORIAL
}

\section{South Africa and national TB control: Are we making progress?}

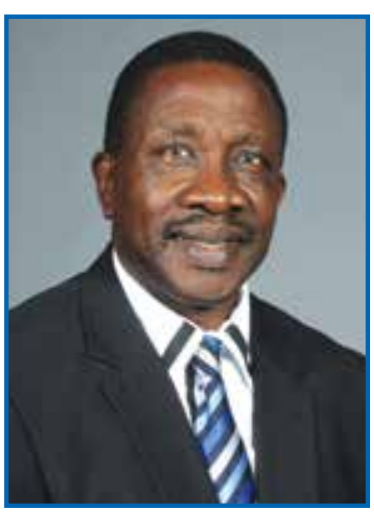

South Africa accounts for the worst global tuberculosis epidemics fuelled by the spread of HIV infection. The tuberculosis (TB) incidence increased from 300 per 100,000 people in the early 1990s to more than 950 per 100,000 in 2012. 'In addition, the country remains one of the countries with the highest TB burden globally, with the World Health Organisation (WHO) statistics giving an estimated incidence of 454,000 cases of active TB in $2015 .{ }^{2}$ This means that about $0.8 \%$ of South Africa's population of 54 million develop active TB disease annually. Of the 454000 TB cases in South Africa in 2015, WHO estimated that about $57 \%(258,000)$ were HIV positive. It also estimated that of 157,505 whose status was known, and who were known to be HIV positive, some $85 \%(133,116)$ were on antiretroviral therapy. ${ }^{3}$ From the same 2015 report, Eastern Cape, KwaZulu-Natal and Western Cape provinces had the highest incidence rates of 692,685 and 681 per 100,000 respectively. The most notable decline was in KwaZulu-Natal where the incidence decreased from 1,185 to 685 per 100,000 over the last five years. ${ }^{1}$

The analysis of the ten leading underlying natural causes of death showed that six of the top ten causes were non-communicable diseases, while the other four were communicable diseases. TB remained the leading underlying natural cause of death in 2015, accounting for $7.2 \%$ of deaths, followed by diabetes mellitus with $5.4 \%$ of deaths. Although tuberculosis has maintained its position as the number one leading underlying natural cause of death, the proportions over time have been declining, whilst proportions for diabetes mellitus, hypertensive diseases, other viral diseases and chronic lower respiratory diseases have been increasing. ${ }^{4}$

A systematic review on TB and poverty identified the contribution of patient costs in sub-Saharan Africa. The authors reported that TB patients in sub-Saharan Africa incur both substantial direct and indirect costs before, during, and after a TB diagnosis. The largest costs these patients incur are for hospitalization, medication, transportation, and treatment or care in the private sector. In addition, caregivers incur substantial indirect or time costs, of providing care or support for TB patients. ${ }^{5}$ It is alluded that patient costs may negatively impact health-seeking behaviours, leading to delays in hospital presentation, further worsening of disease and increasing risk of disease spread. ${ }^{6}$
In South Africa, TB control demonstrates the following features: availability of GeneXpert MTB/RIF as a replacement for sputum smear microscopy, strengthening of case finding in and out of healthcare facilities and greater focus on TB prevention among people living with HIV, with earlier initiation of and scaling up antiretroviral therapy. TB medications are prescribed free of charge in the public health sector. So why do we still have a very high TB incidence rates? There are programmatic and patient-related issues that adversely affect our national TB control programme namely inadequate training of health care practitioners on TB management, anti-TB medications stock outs, problems of patient compliance and continuous change in the TB guidelines, to mention a few.

South Africa's unemployment rate was reported to be 27.7 percent in the third quarter of 2017, the same as in the previous two quarters, which means that 6.21 million South Africans are unemployed. ${ }^{7}$ As earlier alluded in this editorial poverty, economic burden of direct and indirect costs before, during, and after a TB diagnosis on patients may be contributory factors for the low progress in controlling the high TB incidence in South Africa. Therefore, a progressive national economic growth may be a possible focus to shift the negative impact of TB on the South African population. However, with the low current and projected economic growth of under $1 \%$, the TB burden will persist for the near future. South Africa has invested substantial amounts of its health budget on TB control and we need to experience the benefits. However, breaking the national poverty cycle may provide some solution to lowering the high burden of TB in South Africa.

\section{Prof. Gboyega A Ogunbanjo}

Editor-in-chief: SAFPJ

\section{References:}

1. Mayosi MB and Benatar SR. Health and Health Care in South Africa -20 Years after Mandela. N Engl J Med 2014; 371:1344-1353October 2, 2014DOI: 10.1056/ NEJMsr1405012.

2. Global Tuberculosis Control 2016, WHO, Geneva, 2016. Available at www.who.int/ tb/en [accessed on 26 Nov 2017].

3. Global Tuberculosis Control 2016, WHO, Geneva, 2016. Available at www.who.int/ tb/en [accessed on 26 Nov 2017].

4. Statistics South Africa. Key findings: P0309.3 - Mortality and causes of death in South Africa: Findings from death notification, 2015. Available at http://www. statssa.gov.za/?page_id=1856\&PPN=P0309.3\&SCH=6987 [accessed on $27 \mathrm{Nov}$ 2017].

5. Barter DM, Agboola So, Murray MB and Bärnighausen T. Tuberculosis and poverty: the contribution of patient costs in sub-Saharan Africa - a systematic review. BMC Public Health201212:980. Available at https://doi.org/10.1186/1471-2458-12980 [accessed on 27 Nov 2017].

6. Chang B, Wu AW, Hansel NN, Diette GB: Quality of life in tuberculosis: A review of English language literature. Qual Life Res. 2004, 13: 1633-1642. 10.1007/s11136004-0374-1.

7. Trading Economics. South Africa Unemployment Rate 2000-2017. Available at https://tradingeconomics.com/south-africa/unemployment-rate [accessed on 27 Nov 2017] 